\title{
mástico asfáltico. Nueva superficie de rodadura para las autopistas alemanas
}

\author{
mastic asphalt. New wearing surface for german aufobanen
}

PAUL. J FLUSS

(*World Constructionx, núm. 8, agosto. 1959, pág. 33.)

El empleo de másticos asfálticos (Gussaphalt) para pavimentación, tiene una amplia historia de éxitos. Las calzadas y aceras de muchas ciudades y capitales europeas, son la prueba de sus excelentes cualídades de resistencia al desgaste.

El aumento de tráfico rodado ha obllgado a cambiar la composición original del mástico asfáltico, con el fin đe incrementar su resistencia superficial. Utilizando un gran porcentaje de piedra machacada y disminuyendo el contenido de y. áspera. Sin embargo, al tener que colocarse manualmente, su uso no se generalizó, a pesar de sus grandes ventajas técnicas. Śblo después de ciertas mejoras, que hicieron posible su aplicactón a máquina, fué cuando el mástíco asfáltico llegó a adquirir una gran preponderancia. Ahora no sólo ocupa un lugar destacado en la pavimentación de las calles, sino que también se usa mucho en la construcción de las carreteras y autopistas alemanas.

Entre los más importantes planes en que se ha usado el mástico asfáltico, están los tramos de las autopistas alemanas: Frankfurt-Nuremberg; Frankfurt-Colonia; Colonia-Düsseldorf; Düisseldori-Oberhausen; Düsseldorf-Wuppertal; Colonia-
Aachen; Avus-Berlín, y circulto de circunvalación de Berlín.

¿Cuáles son las razones para esta enorme popularidad del mástico asfáltico? De las obras antes mencionadas y de otros proyectos en construcción, se han publicado diversos artículos en algunas revistas alemanas, las cuales resumen las. siguientes ventajas técnicas de los másticos asfálticos:

1) Basándose en el excelente resultado que se ha obtenido en la construcción de travesías, puede considerarse que este mástico es el pavimento asfáltico más duradero.

2) Debido al exceso de asfalto que contiene, posee una gran fuerza de cohesión que lo hace resistente al agrietamiento y completamente impermeable.

3) Su resistencla a la absorción es muy alta. En la ciudad de Kossel, se ha empleado satisfactoriamente en curvas y cruces de calles para resistir el efecto destructivo producido por el giro de los tanques militares. 
4) En su utilización práctica se ha visto que es poco afectado por el clima.

5) Después de colocado no necesita la subsiguiente compactación, como el alisado con rodillos.

6) Su conservación es simple y económica.

El mástico asfáltico, tal como se usa actualmente, se aplica basándose en las "Ordenanzas" de Berlín establecidas en 1953, las cuales, según el Dr. Ing. Paul Wichert, de Dortmund, señalan entre otras cosas:

I. El volumen de huecos de la combinación de áridos minerales, vibrados hasta volumen constante, no puede exceder del $18 \%$.

II. El máximo contenido de asfalto es de cuatro partes en volumen. Esto limita el exceso de esfalto, que ha de ser añadido en la cantidad imprescindible para llenar los huecos.

III. El peso por unidad de volumen del mástico asfáltico será, como minimo, de 2,35 .

Para diversos tramos, que en total sumaron 46 millas $(74 \mathrm{~km})$, de la autopista Frankfurt-Nuremberg, los materiales $y$ dosificación fueron los siguientes:

El asfalto mástico se dosificaba y mezclaba en caliente en plantas mezcladoras, transportándose a obra en camiones amasadores en caliente, cuya capacidad es de 4 a 5 toneladas. Utilízanse carretillas o canaletas, se vierte frente a la máquina de acabado a $400-440^{\circ} \mathrm{F}\left(200-225^{\circ} \mathrm{C}\right)$, según la temperatura ambiente. La operación de acabado consiste tan sólo en maestrear, por medio de un dispositivo de apisonado en caliente. En el mercado existen diversos tipos de máquinas de acabado. Las hay lo suficientemente anchas para abarcar un camino de autopista, que tiene 24 pies $(7,5 \mathrm{~m})$ y se desplazan sobre carriles. Para conseguir una mayor resistencia superficial $s e$ esparce piedra triturada de tamaño comprendido entre los tamices números 4 y 10 , sobre el mástico asfáltico cuando todavía se encuentra caliente y dosificado a razón de 7,5 libras por yarda $\left(4 \mathrm{~kg} / \mathrm{m}^{2}\right)$. La compactación se realiza con un rodillo claveteado, el cual forma sobre Ia superficie un dibujo de aspecto similar al de un barquilio. Los hoyitos hechos con el rodillo claveteado tienen, aproximadamente, $1 / 4$ de pulgada $(6,3$ milímetros) de profundidad. Para mejorar la adherencia se suele usar piedra triturada (gravilla) sobre una caja previa de un $1 \%$ de asfalto. El riego de grava y el cilindrado pueden combinarse con el acabado y pueden desplazarse los aparatos también sobre los carriles.

Basándose en su buen resultado, es de esperar que el mástico asfáltico se utilice a todo lo largo de la pista de circunvalación a Berlín y en la autopista FrankfurtNuremberg, planeada para formar parte de la futura carretera InterEuropa número 5.

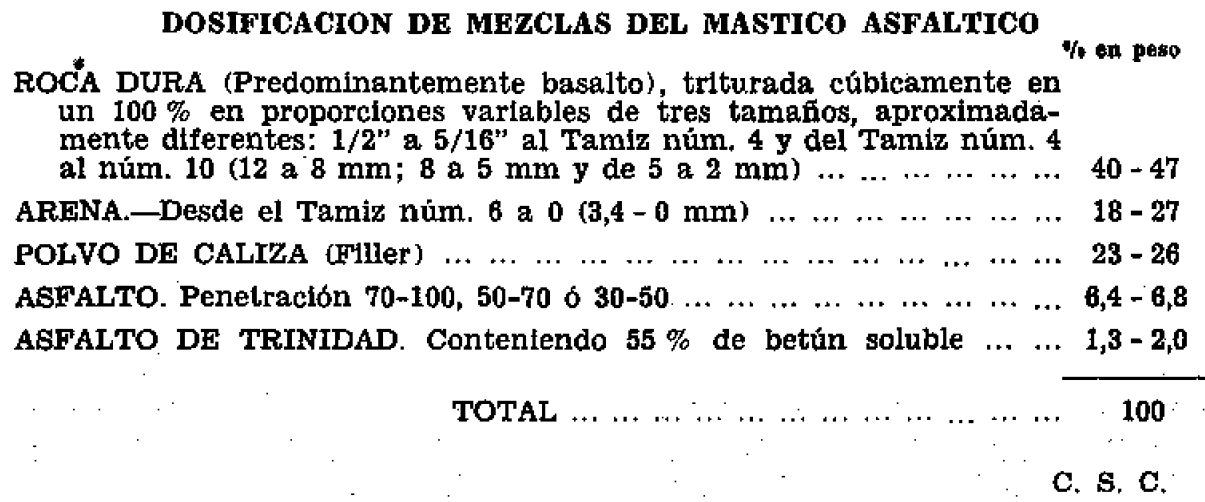

